\title{
Umberto Eco, el último signo del hombre de los signos ${ }^{1}$
}

\author{
Umberto Eco, the last sign of the man of the signs
}

\author{
Jean-Marie Klinkenberg \\ Profesor emérito Universidad de Lieja, Bélgica \\ Miembro de la Real Academia de Bélgica
}

Toda muerte es un escándalo. Pero la de Umberto Eco lo es aún más, ya que su personalidad pareciera que hubiera trascendido los estratos del tiempo. Como especialista en la Edad Media, su vertiginosa erudición y su humanismo hicieron de él un personaje típicamente renacentista. Su sentido crítico, que nunca se dejó atrapar además de parecer un voltariano gustoso, nos permitía ver en él a un orgulloso descendiente de la época de las Luces. $\mathrm{Y}$ es echando una mirada aguda a la sociedad contemporánea, en sus manifestaciones a veces más triviales que Eco da una preciosa contribución a la dinámica antropológica.

Si me refiero a Eco como un especialista de la Edad Media, no es pensando en su célebre novela El Nombre de la Rosa. Es más bien porque sus primeras especialidades fueron la estética y la escolástica medievales. La formación inicial del joven piamontés-nació en Alejandría el 5 de enero de 1932- es la de un filósofo; dicha formación es consagrada en 1954 a una tesis sobre Tomás de Aquino, defendida en la Universidad de Turín. Comienza entonces su carrera de investigador: Eco es profesor de la Universidad de Turín (19611964), profesor asociado en comunicación visual en la Facultad de arquitectura de la Universidad de Florencia (1966-1969), profesor de semiótica en la Universidad de Milán (1969-1971). En 1971 pasa a la Universidad de Boloña en donde se quedará y logrará la titularidad en 1975. De 1976 a 1977 y de 1980 a 1988 será el director del Istituto di Discipline della Comunicazione e dello Spettacolo y de 1986 a 2002, director del programa doctoral de semiótica. De 1993 a 1998 ocupa la cátedra de Laurea in Scienze della Comunicazione y a partir de 1999, es presidente de la Scuola Superiore di Studi Umanistici. Obtiene el título de profesor emérito en el 2007, sin abandonar las responsabilidades académicas: desde 1989 es el presidente del International Center for Semiotic and Cognitive studies de la Universidad de San Marino.

Pero también queremos presentar a Eco como un observador del mundo contemporáneo. Es que, de manera paralela a su carrera académica, se desempeñará en otra que lo llevará a innovar en el mundo de los medios de comunicación, entonces en plena ebullición. El mismo año de su tesis, fue reclutado por la RAI, la radio-televisión del Estado italiano, para la concepción de nuevos espacios culturales. En la prolongación de esta misión, trabaja de 1959 a 1975 en la casa editorial Bompiani, en Milán y colaborará regularmente en varios periódicos como Il giorno, La stampa, Corriere della Sera, La Repubblica, Il Manifesto y sobre todo en $L^{\prime}$ Espresso en donde tendrá una columna semanal a partir de 1965.

Este periodo de formación no solo influirá en las temáticas de investigación de Umberto Eco, sino que también, como lo mostraré al final, en la apariencia general de sus trabajos.

Tanto sus temáticas de investigación como su experiencia en el terreno, harán de él uno de los primeros especialistas de la comunicación

1 Texto leído en la Real Academia de Bélgica bajo el título de Éloge d'Umberto Eco. 
de masas. Esta última se encuentra en pleno desarrollo, lo que produce modos de sociabilidad inéditos al igual que nuevas formas, a las cuales es sensible. Participa así, con los de su generación, en la renovación de la cultura italiana.

Su contribución más importante a este movimiento data de 1962. Es entonces que el esteta, preocupado por la generalidad de los conceptos que explota, se hace conocer con un texto fundador, La Obra abierta (1962), saludada por la crítica y tomada igualmente como referente por todos los creadores de la época (por ejemplo, en literatura, por el Gruppo 63 o en la música por Henri Pousseur). Las exigencias del filósofo continúan manifestándose: lo que conviene buscar, más allá de la variedad en la superficie de las prácticas estéticas y mediáticas, es el sentido. El método se impone entonces: será el semiótico. Y esta es la segunda contribución indiscutible de Eco al pensamiento contemporáneo: $L a$ estructura ausente, introducción a la investigación semiótica (1968).

Si bien la producción científica de Eco tiene carácter proteico -no se cuentan sus obras sobre temas de teoría literaria, pragmática o historia de las ideas- su obra se va haciendo cada vez más semiótica. Dicha obra es marcada por obras de gran aliento como el Tratado de semiótica general (1975) o incluso Semiótica y filosofía del lenguaje (1984), ofrecerá una síntesis original del estructuralismo europeo y de la tradición pragmática anglosajona ilustrada por Charles Sanders Peirce. En la primera tradición el signo es descrito como una maquinaria que funciona con relativa autonomía, lo que Eco criticaría considerando fecundas las técnicas de descripción posibles; en la segunda tradición, el signo está relacionado con las imposiciones sociales y antropológicas que determinan su práctica. De igual forma Eco comprende que no se pueden olvidar las imposiciones corporales y mentales: su ensayo maestro Kant y el ornitorrinco, su última gran contribución a la semiótica (1997), considera así el funcionamiento de las categorías a la luz de las ciencias cognitivas.

Junto a su propia obra, el semiólogo también jugó un papel capital de animador, creando revistas-como $\mathrm{VS}^{2}-$, colecciones científicas, pero sobre todo creando cursos de semiótica, tanto en la Universidad de Boloña como en otros lugares. Detallaré a continuación su actividad al interior de la International Association for Semiotic Studies: de 1972 a 1979, asume la secretaría general de esta joven asociación, luego es el vicepresidente, de 1979 a 1983, antes de convertirse en el presidente honorario. Es en este marco que organiza en 1974, en Milán, el primer congreso mundial de semiótica, una gran fiesta en donde pude ver, algo pasmado, cruzarse a Lacan y Barthes, Jakobson y Kristeva y donde les pude hablar a esos dioses venidos del Olimpo como a seres humanos.

Los méritos de Eco, quien falleció el 19 de febrero de 2016, fueron reconocidos a nivel mundial. Fue profesor invitado en muchos países, de Yale (en donde estuvo en tres ocasiones), Columbia, Cambridge y Oxford al Colegio de Francia y a la Escuela Normal Superior (rue $\left.d^{\prime} U l m\right)$. Fue laureado con varios premios. Doctor Honoris causa de cerca de 40 universidades en una veintena de países, hizo parte de numerosas academias (Academia Universal de las culturas, París; Academia de Ciencias de Boloña. Academia Europea de Yuste, Academia Americana de Artes y Letras, Academia polaca de Artes y Ciencias), incluyendo por supuesto l'Accademia Nazionale dei Lincei, la más antigua del mundo. Tuve el privilegio de hacerlo elegir miembro asociado de la Real Academia de Bélgica el 7 de marzo de 2011.

La actividad de Umberto Eco es tan abundante que es muy complicado atreverse a identificar una línea que se destaque y se imponga. No

2 Versus (o VS, como habitualmente se la conoce) es una de las primeras revistas de semiótica, filosofía y teoría del lenguaje más conocidas y representativas de la comunidad de estudiosos de la semiótica. Fue fundada por Umberto Eco en 1971 quien la dirigió hasta su muerte. Actualmente la directora es la profesora Patrizia Violi. [NdT]. 
obstante correré ese riesgo. Ya que, como me atrevo a afirmarlo, sería falso hablar aquí de dispersión: no hay diez o más Eco sino uno, aplicándole a la frondosidad de los objetos observables una preocupación única.

Pero ¡qué problema! El aporte de Eco se sitúa en efecto en una intersección de disciplinas que tiene como objeto el complejo proceso de la interpretación. Y estas disciplinas son sin duda numerosas y van de la filología a la crítica de arte pasando por el psicoanálisis y la exégesis.

Si miramos en detalle, el problema de la interpretación no se limita solo a los enunciados, término que se acostumbra reservar a las manifestaciones semióticas muy elaboradas: se aplica a todo fenómeno al cual se le puede atribuir un sentido, comenzando por los datos que provienen del mundo. ¿Qué hace el turista en una ciudad desconocida cuando busca saciar su sed, encontrar un teléfono o dirigirse a una estación de transporte, sino interpretar los datos espaciales que se le ofrecen en calidad de signos? ¿Y qué hace el amante de champiñones en una naturaleza que arroja multitud de señales así como la ciudad más congestionada con signos? ¿Qué hace el depredador rastreando a su presa? Ya sea la del historiador, la del científico en su laboratorio o de la bacteria en busca de una molécula de azúcar, toda interpretación es una operación pragmática que procede del encuentro entre tres elementos: un hecho de experiencia; una rejilla de interpretación que permitirá clasificar el fenómeno en particular en categorías generales y esta rejilla está elaborada o movilizada por la instancia interpretante, tercer factor, cuyo papel es capital, ya que son sus necesidades, sus expectativas o sus objetivos que desencadenan el proceso semiótico.

Toda la obra de Eco puede considerarse como una vasta parábola en donde no deja de observar la superposición entre las tres variables.

Eco también estuvo fascinado por la plasticidad y el reemplazo de las rejillas, incluso por el hecho de que algunas de entre ellas logran más o menos ser estabilizadas socialmente, lo que convierte a los hechos fácilmente identificables.
De tal suerte que el proceso interpretativo será más o menos seguro o conjetural (es la base de la distinción que opera entre ratio faciles $y$ ratio difficilis). Se sitúan en los dos extremos del abanico, la actividad científica y la lectura de la obra de arte en donde se encuentra igualmente la investigación policial en la cual Eco también se interesó.

De igual forma, Eco fue sensible a los aspectos accionales del proceso interpretativo. $\mathrm{Si}$ toda interpretación transforma el hecho que se va a interpretar, modifica también al intérprete: afecta por supuesto, aunque fuera en proporciones ínfimas, su capacidad para detectar y discriminar los fenómenos sometidos a su atención como también a sus alcances. Ella coloca pues en movimiento el sistema en su conjunto. Todo investigador, todo Sherlock Holmes, es transformado por sus descubrimientos.

Esta necesaria implicación transformadora del observador se convirtió por supuesto en un lugar muy frecuentado por la epistemología contemporánea. Pero una de las originalidades del aporte de Eco a esta cuestión es la de articularla a la ética: ¿cuál es la postura que debe adoptar el intérprete frente a lo real que se le presenta -o mejor se le presta-?

Para algunos, lo real tiene una existencia estable, y una interpretación no puede ser más que una epifanía de este último, su "lectura fiel". Este realismo que consiste en creer que los hechos tienen un sentido en sí mismos corresponde a una corriente de filosofía del lenguaje que va de Aristóteles a Fodor pasando por Tomás de Aquino y que "entiende comprometer los signos sobre un orden del mundo". La idea de una donación de sentido por la naturaleza de las cosas, es rechazada por el pensamiento contemporáneo. Y Eco, junto a otros entre los que se cuenta a Bruno Latour, insiste en el hecho de que el sentido es una construcción.

Pero acaso, ¿es total la libertad del intérprete? Y las cosas ¿no serían más que lo que de ellas se dice? Sabemos que es en esta dirección que se dirigen las teorías constructivistas (con las cuales se identifican algunos semiólogos 
idealistas, para quienes solo existen relaciones entre los signos, pero nunca de referencia): en el límite, una interpretación es para ellas una impostura en la medida en que ella pretendería decir cualquier cosa del mundo.

La cuestión que aquí se plantea, más que nunca en un momento en que el concepto de "teoría de la conspiración" es objeto de debate público, es el de los Límites de la interpretación. Se reconocerá bajo su apariencia de cursivas, el título de un trabajo de Umberto Eco que en su parábola del Péndulo de Foucault mostró los desaforados extremismos a donde conducía el liberalismo interpretativo.

Sí, la obra de Eco es una parábola. Ella nos revela que el investigador debe recorrer un camino escarpado, sin caer en uno $u$ otro de estos abismos. Por un lado, tenemos el saber científico que es, según la fórmula de Popper, un "conocimiento sin certeza", un saber nunca establecido y siempre en gran medida mítico. Pero, por otro lado, este saber está garantizado por la acción que permite sobre una acción que se resiste y permite al menos conquistar certezas a propósito de lo que esta realidad no es. Y nosotros, caminantes en el bosque del sentido, encontramos estos signos que hacemos nuestros: “Nuestros signos dan razón de lo que eso cómo nos construyen lo que no es" ${ }^{\prime 3}$.

Mencioné, al evocar los recorridos profesionales de Eco, una doble experiencia inicial: una vida de investigador y una vida de hombre de medios. Esta doble construcción influenció sus temáticas de investigación, pero también el estilo general de sus trabajos.

El antiguo columnista se ha caracterizado por poner a disposición todos los conocimientos de avanzada, a asociar un pensamiento teórico exigente con una mirada con frecuencia divertida de los objetos más cotidianos de nuestro entorno.
Este arte poco común se ha podido manifestar de varias maneras: en obras pedagógicas (dirigidas al estudiante principiante que él no desprecia, ofreciendo su delicioso y eficaz Cómo se hace una tesis...1977); en síntesis magistrales, como su texto clásico El Signo (1973) que tuve el privilegio de adaptar al francés permitiendo una verdadera colaboración con su autor, sonriente y cómplice; en múltiples artículos -con frecuencia mordaces pero siempre estimulantes- reunidos en volúmenes; en bellos ensayos ilustrados, como Historia de la belleza (2002) o Vértigo de la lista (2009). $\mathrm{Su}$ producción literaria, ampliamente conocida por el público e inaugurada espectacularmente con el Nombre de la rosa (1980), puede además aparecer como un arranque y algunas veces incluso como una aplicación de los trabajos científicos de Eco. Acabo de sugerir por ejemplo que El péndulo de Foucault (1988) es tanto un thriller como una ilustración de las tesis de Los límites de la interpretación, libro que aparecería poco después (1990).

Finalmente, otros ensayos como ¿En qué creer? (1996), Cinco cuestiones de moral (1997) o Construir el enemigo (2011) muestran que este heredero de los enciclopedistas es también un moralista y un ciudadano valiente.

Suponemos que todo lo que se ha dicho no habría sido si no hubiera habido un hombre como fuente de este trabajo, Un hombre, modelo de bondad y generosidad, siempre humano y olvidadizo de él mismo pero que siempre supo estimular a los demás y confiar en ellos. Hay una anécdota al respecto. A finales de los años 80, acogimos a Umberto en mi universidad, para otorgarle el Doctorado Honoris causa. Como favor, me solicita alejar a los medios de comunicación por ser demasiado intrusivos. Pero justo antes de la ceremonia, una joven estudiante de periodismo se las arregló para atravesar la barrera. Y es con una sonrisa que se preparó para el juego de preguntas inesperadas. Al final de la entrevista, vemos palidecer a la estudiante:

3 Umberto Eco, «Quelques observations en guise de conclusion», in J. Petitot, P. Fabbri, dirs., Au nom du sens. Autour de l'cuvre d'Umberto Eco, Colloque de Cerisy, Paris, Grasset, 2000, p. 582. 
en su excitación ¡se había olvidado de poner el cassette en la grabadora! Entonces, tocado por su angustia, Umberto le da una cita para más tarde con el fin de reanudar la entrevista en paz.

La semiótica con rostro humano que defendió y practicó Umberto Eco es un humanismo; es también un lugar de diálogo. Ya que la palabra de Eco fue la de la $\pi \alpha \varrho \emptyset \eta \sigma i ́ \alpha$ [franqueza] la que apunta a la libertad de decir, en el intercambio entre iguales, la que cubre tanto la autotransformación y el acceso a la verdad.

Versión española de Miguel Ángel Mahecha B., Universidad Surcolombiana 